\title{
EspaÇo geopolítico lusófono: VIDAS em PoRtuguês
}

\author{
Regina Brito
}

\begin{abstract}
RESUMO
Língua - vidas em Português (2004), de Victor Lopes, mostra a presença da cultura e da língua portuguesa em diferentes partes do mundo, tomando como representação do universo lusófono: Goa, Moçambique, Brasil, Portugal e Japão. Nosso trabalho parte da hipótese de que opiniões, sentimentos, práticas e comportamentos manifestados em Português por indivíduos comuns presentes no documentário indiciam elementos significativos para uma compreensão de lusofonia. Pelo lugar social que ocupam, suas falas são tomadas como estilos de vida englobantes de opiniões sobre a língua portuguesa e representações da cultura à qual pertencem, enfatizando relações entre os sentidos locais e as significações advindas de fora do país. Encontrar o ponto de equilíbrio entre o local e o global, assim como as tensões históricas entre valores (tradição em oposição à inovação, por exemplo) do universo lusófono são consequências da análise a partir do que o documentário nos lega enquanto significação. Assim, por essa manifestação discursiva, outras linhas de entendimento de lusofonia podem surgir por meio de uma chave de leitura que neutraliza ou complexifica as oposições, construindo uma representação de lusofonia como um espaço marcado pelo encontro de diferenças que não necessariamente estão em competição, mas, ao contrário, como um lugar supranacional em permanente diálogo.
\end{abstract}

Palavras-chave

Estudos Lusófonos; identidade lusófona; Português no mundo

\section{LUSOPHONE GEOPOLITICAL SPACE: VIDAS EM PORTUGUÊS}

\begin{abstract}
Língua - vidas em Português (2004), by Victor Lopes, shows the presence of Portuguese culture and language from around the world; the basis of representation of the lusophone universe are Goa, Mozambique, Brazil, Portugal, and Japan. Our work stems from the hypothesis that opinions, feelings, practices and behaviors manifested in Portuguese by common individuals present in the documentary can indicate significant elements for the comprehension of Lusophony. It is by the social spaces they occupy that their speech can be taken as a way of life, which encompasses opinions of the Portuguese language and representations of the culture they belong to, emphasizing relations between local meanings and those originating from abroad. Finding the balance between the local and global, just as the historic tensions among values (tradition in opposition to innovation, for example) of the lusophone universe are consequences of the analysis that the documentary bequeaths us as significant. As such, from this discursive manifestation, other lines of thinking the lusophone concept emerges through a reading key that neutralizes or complexifies oppositions, constructing the representation of Lusophony as a space marked by the meeting of differences, not necessarily in competition with each other, but rather, a supranational space in permanent dialogue.
\end{abstract}

KEYWORDS

Lusophone Studies; lusophone identity; Portuguese in the world 
E a certa altura, o Português perdeu o dono. Mia Couto (Língua - vidas em Português, 2004)

\section{ESPAÇO GLOBALIZADO E LUSOFONIA}

A epígrafe que abre este artigo, extraída do documentário Língua-vidas em Português (2004) (também evocado no título), foi o mote que orientou, nesta escrita, as reflexões em torno dos Estudos Lusófonos. Partimos de considerações sobre o espaço globalizado e sua relação para a construção de uma ideia de lusofonia, para, na sequência, trazer à baila depoimentos de algumas das "vidas em Português", retirados do documentário.

Compreender o "espaço globalizado" impõe vivenciarmos o acelerado desenvolvimento dos sistemas de comunicação e com ele a diminuição das distâncias e do tempo (a compressão espaço-tempo, de Harvey' ou a supressão das barreiras tempo/espaço, de Bauman²); de presenciarmos o avanço das mídias digitais, estreitando limites entre a privacidade e a autopublicidade; de vermos o surgimento de novos blocos econômicos para integrar mercados (mas não, necessariamente, pessoas); de observarmos a rápida disseminação de informações sobre dados de quaisquer naturezas (a sociedade informacional, de Castells $s^{3}$.

No entanto, a sociedade capitalista parece não sofrer abalos com essas movimentações que auxiliam na caracterização do espaço globalizado, pois a cultura massificada continua a se sobrepor às locais. Neste cenário, a globalização surge como um processo que busca anular diferenças, impondo uma cultura dominante; ou seja, é um processo que tudo padroniza e que tende a eliminar o particular. Em alguma medida, a lusofonia poderia ser um movimento de resistência que se alimentasse, justamente, da valorização e da recomposição dos sentidos e dos valores locais.

A globalização, entretanto, não ocorre impunemente, pois está em andamento uma reação a esse processo de homogeneização no qual a produção local de cultura se coloca contra a globalização e a indústria cultural, robustecendo seus elementos locais. Dessa forma, a globalização na contemporaneidade se defrontou com o ressurgimento da reafirmação das identidades particulares (étnicas, regionais, sexuais, de gênero, etc.) e, naturalmente, a própria noção de identidade, que se solidificou com a ascensão de nações e sofreu transformações em decorrência desses novos tempos:

\footnotetext{
1 "À medida que o espaço parece encolher numa 'aldeia global' de telecomunicações e numa 'espaçonave terra' de interdependências ecológicas e econômicas (...), e que os horizontes temporais se reduzem a um ponto em que só existe o presente (...) temos de aprender a lidar com um avassalador sentido de compressão dos nossos mundos espacial e temporal" (Harvey, 2004, p. 219).

2 "A mudança [na condição da existência humana] é a nova irrelevância do espaço, disfarçada de aniquilação do tempo. (...) o espaço pode ser atravessado, literalmente 'em tempo nenhum'; cancela-se a diferença entre 'longe' e 'aqui'. O espaço não impõe mais limites à ação e seus efeitos, e conta pouco, ou nem conta" (Bauman, 2001, p. 136).

3 "O que é específico ao modo informacional de desenvolvimento é a ação do conhecimento sobre os próprios conhecimentos como principal fonte de produtividade. (...) Um círculo virtuoso de interação entre as fontes de conhecimentos tecnológicos e a aplicação da tecnologia para melhorar a geração de conhecimentos e o processamento da informação" (Castells, 2005, p. 54).
} 
a globalização produz diferentes resultados em termos de identidade. A homogeneidade cultural promovida pelo mercado global pode levar ao distanciamento da identidade relativamente à comunidade e à cultural local (...). A dispersão das pessoas ao redor do globo produz identidades que são moldadas e localizadas em diferentes lugares e por diferentes lugares.

(Woodward, 2000, pp. 21-22)

Nessa conjuntura, nova representação de lusofonia emerge a partir dos processos de independência de meados da década de 19704. A princípio, entende-se a lusofonia como uma conexão, no plano institucional, dos países que assumiram o Português constitucionalmente como oficial. Consequentemente, a herança portuguesa manteve-se como uma das bases do caldo cultural desses países; assim, de certa forma, pensar numa lusofonia viável (Brito, 2017) supõe estabelecer ou reestabelecer vínculos históricos e culturais entre países de diferentes regiões do globo, partindo de elemento comum - a língua portuguesa - que, necessariamente, se reveste de normas distintas em cada localidade. Além desse elo linguístico, a lusofonia significativa deve partir do complexo de relações culturais que subjazem aos que dela fazem parte, como refere Martins (2006, p. 58):

\begin{abstract}
a lusofonia só poderá entender-se como espaço de cultura. E como espaço de cultura, a lusofonia não pode deixar de nos remeter para aquilo que podemos chamar o indicador fundamental da realidade antropológica, ou seja, para o indicador de humanização, que é o território imaginário de paisagens, tradições e língua, que da lusofonia se reclama, e que é enfim o território dos arquétipos culturais, um inconsciente colectivo lusófono, um fundo mítico de que se alimentam sonhos.
\end{abstract}

Há, contudo, quem veja a lusofonia como um projeto vazio e de aplicação problemática, justamente por causa da multiplicidade de discursos e de definições (ou indefinições) sobre o denominado universo lusófono. Se há autores que identificam certa fragilidade do projeto lusófono, há os que defendem o equilíbrio no meio da multiplicidade discursiva, principalmente pela necessidade de reconhecimento da relação entre a diversidade e a unidade linguístico-cultural. Por exemplo, Cunha (2012, p. 260) propõe uma compreensão de lusofonia como "ponto de confluência de identidades sociais distintas e dispersas". Como esse autor procura trabalhar a lusofonia no âmbito das relações entre identidade e cultura, seu intento é o de tentar ultrapassar a dimensão linguística dessa questão, sem, contudo, negá-la para poder usá-la como complemento - e não como ponto final - das discussões. Nessa mesma perspectiva,

a Lusofonia adjetivada como 'viável', como 'possível', como 'admissível' deve ter sua identidade construída numa dinâmica contínua de respeito, conhecimento, reconhecimento e legitimação uns dos outros, em que

\footnotetext{
${ }^{4}$ Referimo-nos, aqui, aos países colonizados por Portugal cuja independência ocorre entre 1974 e 1975, após a Revolução dos Cravos: Angola, Cabo Verde, Guiné-Bissau, Moçambique, São Tomé e Príncipe (na África) e Timor-Leste (na Ásia).
} 
vamos pincelando diferenças e afinidades. Uma Lusofonia só pode ser 'legítima', na medida em que perceba os diferentes papéis que a língua portuguesa assume em cada localidade, que se construa pela evocação de sons de sotaques vários e que, por fim, aponte para uma conceituação desvinculada de egocentrismos e/ou desconfortos que a palavra LUSOFONIA por vezes carrega, em discursos retrógrados, por sua identificação com uma centralidade da matriz portuguesa em relação aos outros países da CPLP (Comunidade dos Países de Língua Portuguesa), que não faz sentido. A lusofonia "autêntica" não tem um centro, mas centros em toda a parte. (Brito, 2017, p. 1045)

A lusofonia aponta-se, portanto, como um espaço de conciliação da diversidade linguística (em relação às variedades da língua portuguesa e às línguas nacionais/locais) e cultural (com diferentes percursos e práticas socioculturais, padrões, vivências, etc) por meio da unidade do português. Por isso, é fundamental reconhecer, defender e legitimar o direito à coexistência de várias normas e subnormas do Português em todos os espaços lusófonos, assim como das línguas nacionais existentes, pautando-se num princípio de "integração entre unidade/variedade" (Brito, 2013, pp. 57-59), capaz de dar sentido à edificação de uma ambiência lusófona.

Entendemos que o espaço simbólicos em que se constitui a lusofonia, não pode apenas envolver os sentidos racionalmente articulados, mas deve, também, englobar memórias, tradições, hábitos e valores que perpassam e constituem cada um dos países da CPLP e dos demais espaços da diáspora em que o Português se faz presente para, dialogicamente, assentar os significados das muitas lusofonias que constituímos.

A lusofonia - uma totalidade de sentidos distintos baseados num denominador comum, que se abre dicotomicamente em língua e cultura - não é, como sabemos, um conceito ausente de problemas, especialmente quando se passa do plano conceitual para a concretude da vida. Como afirma Fiorin (2010, p. 18), "um dos problemas das entidades supranacionais (no caso da lusofonia, a entidade transnacional é a CPLP) é que eles são um espaço jurídico, político, econômico, financeiro, monetário, mas não um espaço identitário". Dessa maneira, não basta apenas pensar num espaço supranacional comum para trocas econômicas e políticas, se não houver um lugar para o sentimento de pertencimento a um grupo que ultrapassa a identidade nacional sem, contudo, negá-la. Assim, é possível propor a lusofonia (e as identidades que ela pode subsumir) como um contrato em relação aos sujeitos participantes (tal como um contrato de nacionalidade) no qual uma parte da nacionalidade é preservada e, ao mesmo

\footnotetext{
5 "A lusofonia pode ser compreendida como um espaço simbólico linguístico e, sobretudo, cultural no âmbito da língua portuguesa e das suas variedades linguísticas que, no plano geo-sociopolítico, abarca os países que adotam o português como língua materna e oficial (Portugal e Brasil) e língua oficial (Angola, Cabo Verde, Moçambique, São Tomé e Príncipe e Guiné-Bissau (...) e Timor-Leste (acrescente-se nesse rol de oficialidade do português a Guiné-Equatorial). Entretanto, não se pode restringir a lusofonia ao que as fronteiras nacionais delimitam. Nesse modo de conceber a lusofonia, há que se considerar as muitas comunidades espalhadas pelo mundo e que constituem a chamada 'diáspora lusa' e as localidades em que, se bem que nomeiem o português como língua de uso, na verdade, ela seja minimamente utilizada: Macau, Goa, Ceilão, Cochim, Diu, Damão e Málaca. Além disso, a lusofonia é inconcebível sem a inclusão da Galiza" (Brito, 2010, p. 177).
} 
tempo, lhe é acrescida uma nova "carga" de sentidos advindos das "outras lusofonias". É esse aspecto que passamos a discutir a seguir.

\section{IDENTIDADES DA/NA LUSOFONIA}

E hoje eu já andei os continentes todos, mas onde eu gosto mesmo, os países onde eu gosto de trafegar, não sei se é a força da língua, mas são os países de lusofonia. Eu vejo uma identidade entre todos eles. Martinho da Vila (Língua - vidas em Português, 2004)

A identidade não pode ser considerada um traço natural e inato ao indivíduo ou a uma coletividade. Como Cunha (2012, p. 263) aponta, é preciso perceber quais os elementos participantes da construção da identidade em seus diferentes níveis: a identidade dos grupos naturais (como a família e a comunidade local), a identidade nacional (como uma comunidade imaginada) e as identidades supranacionais que surgem como nova forma de fidelidade pessoal. São nesses diferentes níveis que as identidades estão, a todo o momento, buscando definições legitimadoras de seu estatuto, mas quase sempre essa busca é construída a partir de uma ideia de unidade de sentido ("a" nação, "a" língua, "a" sociedade, etc.), ou seja, como um em-si com consciência de si mesmo. Entretanto, é quase consensual pensar que a noção de identidade não pode mais comportar apenas a ideia de uma única unidade de sentido: "a unidade da identidade é, portanto, utópica (fantasiada ou até mesmo paradoxal), pois se fundamenta, se estrutura e se constrói com base na diferença e na divisão à procura da totalidade" (Brito, 2013, p. 23).

A construção da lusofonia passa, portanto, pela questão da identidade. Apesar de se pensar numa identidade lusófona fundada no binômio língua/cultura, é preciso colocar a questão identitária em perspectiva: primeiro, porque ela não é estanque e historicamente imutável; depois, porque uma mesma pessoa possui diferentes identidades que se sobrepõem sem obrigatoriamente se excluírem (familiar, profissional, local, etária, nacional e, talvez, supranacional). Assim, um homem pode ser, ao mesmo tempo, paulistano, paulista, brasileiro, médico, filho de alguém, marido de alguém, e, também, lusófono. A simplicidade desse exemplo pode nos ajudar a pensar nas bases que construiriam uma identidade lusófona.

Se a identidade pode ser entendida como uma narrativa de busca, ela necessariamente passa pelo olhar do outro (Brito, 2013, pp. 22-23). Dessa maneira, a construção da identidade possui uma dimensão mais ou menos controlada pelo sujeito, mas sempre delimitada pelo reconhecimento que o outro precisa fazer da identidade alheia, mesmo que seja apenas em certo grau de abstração. As identidades sociais possuem uma estrutura simbólica historicamente constituída (como determinada cultura nacional), uma dimensão definida pela imposição de uma organização institucional que gera um efeito de sentido de objetividade (como a palavra da Igreja, do Estado e dos partidos políticos) e uma dimensão individual, que pode estabelecer uma tensão com os efeitos de objetividade da identidade imposta. Por isso, a identidade não pode assumir apenas um sentido de semelhança (o em-si mesmo): é preciso reconhecer também as diferenças presentes 
nas identidades que podem mudar conforme a necessidade e a conjuntura - ou seja, "é necessário ao sujeito reconhecer-se como distinto e, ao mesmo tempo, como imutável e contínuo, apesar de eventuais variações de contexto" (Brito, 2013, p. 29).

A não unificação de identidades é um fato que leva as contradições e as discrepâncias entre o nível individual e coletivo a serem obrigatória e recorrentemente negociadas (Brito \& Hanna, 2010, p. 77). No caso, focalizamos, sobretudo, a questão da negociação das identidades, pois essa é a base para se reconhecer a existência de múltiplas identidades e suas lógicas de desenvolvimento. Seria, então, possível pensar uma forma de construção da identidade que privilegiasse uma mistura maior e que pudesse suportar uma constante coexistência de elementos semelhantes e diversos, mas não completamente idênticos; assim, teríamos uma identidade fundada na heterogeneidade, cujos laços seriam fortes o suficiente para conciliar a unidade e a diversidade defendida por vários estudiosos.

Em certa medida, foi o que fizeram alguns grupos imigrantes minoritários no Brasil. Japoneses e libaneses, por exemplo, procuravam moldar a sua identidade de imigrantes à identidade nacional brasileira que nem sempre os aceitou. Assim, em uma constante negociação identitária, esses imigrantes conseguiram mostrar aspectos positivos de sua presença para a sociedade brasileira. A partir dessa situação sócio-histórica no Brasil, ilustramos o conceito de identidade hifenizada, conforme o historiador norte-americano Jeffrey Lesser, que aponta para o fato de a identidade hifenizada possibilitar ao imigrante usar, em determinadas situações, sua identidade étnica original em proveito próprio e, em outros momentos, usar a sua identidade brasileira para obter as mesmas vantagens que os demais brasileiros. Para Lesser (2001, p. 27),

as etnicidades trazidas e construídas por esses imigrantes eram situacionais, e não 'identidades primordiais imutáveis'. Em diversos momentos, os imigrantes e seus descendentes puderam abraçar sua 'niponicidade' ou sua 'libanicidade', tanto quanto sua 'brasilidade'. A etnicidade muitas vezes cruzava com o nacionalismo (brasileiro ou não), tornando extremamente flexíveis essas identidades.

Por isso, é comum no Brasil o uso de expressões como nipo-brasileiro, sino-brasileiro, líbano brasileiro e, mais recentemente, em tempos de politicamente correto, a de afro-brasileiro. Aplicando esse conceito ao campo lusófono (e retirando o sentido etimológico de referência ao povo "luso", ressemantizado para a questão de uma identidade que nos aproxima e nos distingue), postula-se pela existência de identidades lusófonas "hifenizadas": um luso-português, um luso-brasileiro, um luso-timorense (ou o inverso disso tudo) e assim por diante, o que permitiria manter a identidade nacional de cada um e, ao mesmo tempo, acrescentar a identidade transnacional lusófona. Esse critério poderia ser usado para nomear as culturas como múltiplas e entrelaçadas, tal como existe em relação às variedades de língua ${ }^{6}$. Nessa direção, pode-se ser, ao mesmo tempo,

\footnotetext{
${ }^{6}$ Há assim uma correlação entre as noções de identidade desenvolvidas neste trabalho e a variação e a nomeação da lín-
} gua, como supranacional (a língua portuguesa), nacional (Português brasileiro, Português europeu, Português angolano, 
uno e diverso a partir da mobilização identitária que um sujeito poderia realizar a depender da situação (espaço) e do momento (tempo) em que se insere, já que um único indivíduo ou uma só coletividade tem identidades fluídas e móveis, que podem ser reconhecidas em diferentes perspectivas e, assim, apresentar distintas definições sobre eles.

É dessa maneira que se deve buscar, numa concepção possível de lusofonia, amplificar os exemplos que possam reforçar o conceito de "integração entre unidade/variedade" já mencionado. Uma saída mais prática para isso talvez seja, justamente, encontrar casos de encontros e interações culturais, tanto nos estudos tradicionalmente voltados à literatura, quanto nas práticas cotidianas dos indivíduos que, efetivamente, dão vida à lusofonia. Nesse sentido, no contexto da globalização e da lusofonia, cada povo não pode ser simplesmente um consumidor de produtos e sentidos culturais ou receptáculos vazios a serem preenchidos, mas devem ser interpretadores e produtores de cultura, seja ela vinda de fora, seja ela tendo como referencial sua tradição local.

Nos depoimentos extraídos do Língua - vidas em Português (2004) tomados para as reflexões seguintes, podemos identificar uma espécie de "personagem social" bastante significativa, por fazer a passagem entre a sua tradição local e o espaço do outro no qual se insere, interpretando e (re)valorizando alguns traços desse novo espaço de significações.

\section{MOVIMENTO DOS SUJEITOS LUSÓFONOS NO ESPAÇO DA LUSOFONIA}

Falamos a mesma língua, mas ela não é falada da mesma maneira. Quando estamos nos comunicando, sentimos isso; essa vontade de aproximação e ao mesmo tempo a distância que existe entre as maneiras de ser. Teresa Salgueiro (Língua - vidas em Português, 2004)

Apesar da redundância aparente do subtítulo acima, entendemos ser preciso demarcar tanto os sujeitos que se movimentam, como o espaço pelo qual eles se movimentam. Isso porque a questão imigratória no universo lusófono é bastante complexa e, diante de tantas possibilidades, delimitamos o nosso interesse e o foco dado pelo documentário em questão. Assim, apesar de cientes de que os imigrantes lusófonos estão presentes em diversos países não-lusófonos, restringimos nossas considerações aos que circulam pelos países da lusofonia porque são eles os responsáveis pela manutenção e variação de significações linguísticas e culturais ligadas ao universo lusófono, à cultura particular de cada um dos imigrantes e à maneira como eles podem fazer circular essas significações e construir novas a partir do contato com outros sujeitos.

Essas questões foram suscitadas pelo documentário Língua - vidas em Português (lançado em 2004), dirigido por Victor Lopes, que apresenta um painel da presença da língua portuguesa pelo mundo. A partir dele, observamos a constância da herança cultural e linguística do ex-colonizador português, convivendo com as particularidades

Português moçambicano, etc), regional (Português dos Açores, Português sulista) e local (Português carioca, Português mineiro, etc) equivale ao que foi dito em relação à identidade de uma pessoa. 
culturais de cada espaço. Além disso, o filme revela diferentes sotaques surgidos a partir do contato com várias línguas e do uso efetivo da língua portuguesa. Por meio desses elementos, é possível refletir sobre transformações de sentidos derivados da relação entre a identidade e a alteridade no espaço lusófono supranacional em comum.

Nesta secção, serão, portanto, observadas relações diversas entre brasileiros, portugueses, macaenses, angolanos, moçambicanos, guineenses etc, que estão ou não em seus respectivos países de origem e têm seus pontos de vista e opiniões captados pela câmera do diretor.

O documentário permite pensar que a ideia da troca de sentidos entre sujeitos não necessita de um espaço material e concreto em comum para por em prática a imagem mesma da lusofonia. No próprio filme, a noção espacial é dilatada pelos cortes que introduzem cenas gravadas em espaços distantes, o que mostra o movimento de ultrapassar os limites geopolíticos dos Estados nacionais. Pode-se, deste modo, estabelecer a relação e a interação entre identidades e alteridades que alternam seus estatutos conforme a perspectiva adotada (global ou local). Neste caso, a questão identitária não é tomada em termos essencialistas, pois há uma série de representações sociais que são mobilizadas conforme o contexto, o espaço e a situação em que cada um dos sujeitos está inserido. Assim, o fato de ser imigrante é apenas contingencial, o que não exime de pensarmos nas dimensões política e social dos indivíduos que participam do documentário.

Outra ressalva é quanto ao fato de não nos atermos aos discursos a respeito da língua portuguesa ou da cultura de cada um dos países (ou de outros países membros da CPLP) proferidas por personalidades destacadas no documentário (como Mia Couto, José Saramago, João Ubaldo Ribeiro e Martinho da Vila) porque optamos pelo discurso dos que possuem poucas oportunidades para expressar sua visão de mundo e para desenvolver seu ponto de vista a respeito de temas que lhes dizem diretamente respeito. Por isso, centramos o foco sobre os imigrantes lusófonos, isto é, o imigrante cuja origem e experiência estrangeiras ocorrem no espaço geopolítico da lusofonia.

Nessa dinâmica da troca de significados entre sujeitos e espacialidades, que os determinam de modo identitário (tanto no plano material como no plano simbólico), novas significações são transportadas para outros espaços, assim como sentidos locais são deslocados por um novo traço criado pela presença da alteridade. Por essa razão, encaramos o universo lusófono representado no documentário como uma abstração na qual a troca intersubjetiva de sentidos pode conduzir-nos a uma ideia de lusofonia como um espaço de tensão entre a inovação e a tradição.

Esta oposição tem como base a observação de que a elaboração identitária oscila entre os pares tradição/modernidade e hibridismo/mistura. Além disso, esses pares opositivos devem ser vistos como processos inerentes à construção e à negociação dessas mesmas identidades, pois é assim que se pode pensar em uma tradição moderna (e, talvez, em seu contrário, uma modernidade tradicional) em que o passado se mistura com o presente, ao mesmo tempo em que orienta a construção de um futuro em um universo de sentidos como a lusofonia. É dessa maneira que, como hipótese, entendemos qual seria uma das funções dos imigrantes lusófonos: estabelecer ligações entre as 
diferentes culturas lusófonas, como uma espécie de costura de uma colcha de retalhos disforme, podendo causar certo estranhamento nas variações e nas mudanças que esse contato pode estabelecer no âmbito das culturas lusófonas.

Dessa forma, entendemos esta proposta como uma solução para o que Fiorin aponta sobre as bases de uma identidade comunitária, baseada na política, na cultura e na língua (2011, p. 122). Haveria, assim, espaço para a articulação da diversidade em uma base unitária a partir da qual seriam reconhecidas as significações particulares e próprias da lusofonia.

Esse seria, por exemplo, o caso dos estudantes e namorados Sofia Meireles e Uliengue Almeida. Ela é moçambicana, ele é angolano e ambos são estudantes, ou seja, já temos três identidades diferentes, uma profissional e duas ligadas à origem geográfica no universo lusófono. Em dado momento do documentário (6'45"), ela afirma gostar do centro velho de Lisboa porque possui um "ambiente de aldeia", no qual as pessoas são mais próximas e se conhecem. Essa é a maneira, então, pela qual ela identifica uma familiaridade perceptiva de sua própria história, ao mesmo tempo em que usa esse traço familiar de proximidade para qualificar o espaço sobre o qual ela está falando, para, então, distingui-lo de outros espaços que foram atravessados por ela na cidade.

Dessa forma, apesar de serem jovens e imigrantes (teoricamente inseridos em uma grande e global cidade europeia), eles (re)valorizam uma Lisboa histórica e não um lugar moderno e globalizado. Esses mesmos jovens aparecem um pouco depois (9'07"), caminhando no Porto e com a voz de José Saramago em uma narração em off discorrendo sobre o Padre Vieira e a tradição da palavra. Valorizando o passado e o local, esses jovens representam uma modernidade que não apaga ou exclui as características de uma localidade (porque não fazem parte de uma globalização totalizante), mas, ao mesmo tempo, não se lamentam pela superação do passado pelo presente, conforme a fala de Saramago indica. Por isso, entendemos que o jovem casal dessa cena sintetiza a oposição entre passado e presente, antigo e moderno, centro e periferia, ex-metrópole e ex-colônia, sem, necessariamente, excluir um polo para incluir o outro. A oposição conceitual é assim suspensa ou misturada para que se viva o momento do encontro de identidades distintas, que podem se fazer compostas, mutáveis, incertas e fluídas quando precisam ou querem se adaptar às novas situações que o espaço de acolhimento (nem sempre positivo) propicia.

Aparecem outros jovens imigrantes em outro momento do documentário, agora somente angolanos. Dilo Monteiro mostra o centro comercial da Mouraria, também em Lisboa, onde há um "cruzamento de várias culturas" (palavras dele), sobretudo africanas. Aparecem no filme a comerciante guineense Fátima Embaló (da "Mercearia Africana") e o casal macaense Dai Shaori e Liandi Xu, donos de uma loja de roupas no mesmo lugar. O centro comercial poderia representar, pelo documentário, o simulacro do espaço lusófono: um lugar de comércio que conta com a participação de sujeitos de diferentes partes da lusofonia, cuja capacidade de convivência e de contato revela a tolerância em relação ao diferente e ao inesperado.

Ao lado de Dilo Monteiro, dois amigos também narram, distintamente, sua situação. De um lado, Jardel Vieira afirma que o centro comercial mostra uma grande mistura 
representativa da globalização pela qual a Europa está passando. De outro, André Mendes diz que não há diferenças entre eles e os jovens de França, da China e da América, pois os gostos e os projetos de vida são os mesmos (talvez um reflexo da padronização imposta pela globalização). Por fim, a conversa é encerrada com Dilo Monteiro que observa que o multiculturalismo é um fato recente na Europa (ao menos no momento em que sua fala é gravada), mas já estava presente há muito tempo nas antigas colônias. Essa opinião, de certa forma, realiza uma espécie de neutralização dos sentidos, pois suspende a oposição entre o 'lá' (ex-colônia) e o 'aqui' (ex-metrópole). Assim, o ponto de vista desses jovens imigrantes e o modo como refletem e articulam seus discursos mostram uma percepção e, acima de tudo, uma experiência atualizada a respeito da diversidade em relação às práticas e aos valores culturais inseridos na dinâmica lusófona.

É ainda Dilo Monteiro quem assinala uma das experiências mais significativas do documentário (aos 38'10"). Ele frequentemente vai ao bar da Tia Alice, uma portuguesa cantora de fado. Jovens que representam a modernidade e a experiência multicultural mostram o que é possível ao multiculturalismo, defendido ao retomar e valorizar a tradição lusitana representada pelo fado cantado por Tia Alice. É no espaço do bar que a unidade (que permite a comunicação entre jovens e velhos, imigrantes e locais) e a diversidade (da música do outro, da experiência do outro) se conciliam para formar uma imagem de lusofonia que é, em seu limite, vivida e experienciada por diferentes sujeitos. Nesse caso, a oposição entre local/tradicional e exterior/moderno também é suspensa (como no exemplo do casal anterior). Desse modo, observamos que o ser lusófono não está diretamente ligado a uma única nacionalidade, nem um país possui a prevalência de dizer o que é ou deixa de ser lusófono. Falar Português e estar aberto a novas experiências de sentido advindas do outro parecem ser, no caso do documentário, algumas das poucas características necessárias para se estabelecer e sustentar a existência do universo lusófono.

A partir dessa cena, podemos especular sobre as práticas culturais e linguísticas desses sujeitos imigrantes. No caso, a postura de circular por um universo cultural que não é seu, do ponto de vista histórico e social, faz pensar que uma das maneiras de o imigrante lusófono realizar suas ações é por meio da postura de um camaleão, tal como Landowski (2002) o conceitua: como um sujeito que circula, com certa habilidade, por dois universos distintos de significação, o seu de origem e o da sociedade de acolhimento. Assim, ele pode usufruir de algumas benesses que a sociedade de acolhimento lhe oferta, mas sem com isso perder as características que o diferem dessa mesma sociedade e que o mantém como um imigrante, que porta uma maneira de falar, um jeito de encarar sua vida, valores sociais próprios ao seu grupo, determinados gostos musicais, gastronômicos, entre outros hábitos.

É, então, por meio desses sujeitos comuns em suas falas, comportamentos, reflexões, paixões e desejos, que procuramos por um lado pouco tratado da lusofonia. Partimos do princípio de que para a lusofonia tornar-se uma realidade bem estabelecida, legitimada e enraizada nos países nos quais ela deve estar presente (ao menos no plano formal e político), é preciso que ela seja vivenciada por todos os cidadãos. Além disso, 
ainda que a conciliação não seja completamente possível - porque abriria a possibilidade de uma homogeneidade indesejada - o que consideramos fundamental para esse espaço virtual é a coexistência e o reconhecimento de diferentes vidas, como ilustramos acima.

Cabe assinalar, ainda, que o interesse comunitário ou o valor cultural são negociados nos interstícios, lugar em que a necessidade de suplantar narrativas de subjetividades essencialistas faz com que se enfatize o resultado da articulação social das diferenças culturais, atribuindo autoridade aos hibridismos culturais que emergem em momentos de transformação histórica (Brito \& Hanna, 2010, p. 85).

Para compreender como a dinâmica identitária se desenvolve no contexto da lusofonia, voltamos ao conceito de identidade hifenizada já citado. Lesser (2001), ao estudar as relações entre imigrantes e descendentes de origem asiática no Brasil, observou que eles ora se consideravam brasileiros, ora recorriam às origens identitárias de seus pais, conforme quisessem evidenciar supostas características (como, por exemplo, a habilidade matemática, que seria, assim, derivada de um suposto caráter nipônico, ou a facilidade no trato pessoal, característica dita brasileira). Entendemos haver um movimento semelhante dos imigrantes em suas relações de aproximações e os distanciamentos a respeito do contato com outras culturas. No entanto, ao contrário dos imigrantes no Brasil, a diferença entre os imigrantes lusófonos do espaço português não é tão distante e a possibilidade de mistura e de uma "hifenização" pode vir a ser maior do que a que ocorreu no caso brasileiro tratado por Lesser.

\section{LUSOFONIA, LUSOFONIAS, ESTA E OUTRAS}

Não há uma língua portuguesa, há línguas em Português.

José Saramago (Língua - vidas em Português, 2004)

Uma possível saída para essa dinâmica identitária, conforme pontua Cunha (2012), é a de encarar a lusofonia como uma identidade mais enfraquecida, mas ainda capaz de organizar redes de significação do imaginário lusófono. No entanto, para isso, seria preciso considerar as narrativas identitárias de cada um dos países do espaço lusófono, não para superá-las ou substituí-las, mas para cruzá-las (o autor nomeia esse expediente de "nós de significação", p. 269) com o intuito de produzir possíveis desdobramentos, ressignificações e diálogos entre a tradição e a modernidade. É nesse momento que a ideia de identidade hifenizada parece ganhar mais força.

Neste ponto, evocamos Lourenço a respeito do projeto lusófono: "se queremos dar algum sentido à galáxia lusófona, temos de vivê-la, na medida do possível, como inextricavelmente portuguesa, brasileira, angolana, moçambicana, cabo-verdiana ou são-tomense" (2001, p. 112). Acrescente-se, contudo, que a lusofonia só será real se os indivíduos a viverem em uma dimensão única e, ao mesmo tempo, local da lusofonia e de cada nacionalidade. Vivendo, assim, com a sensação de um "ambiente de aldeia" (evocado no documentário pela moçambicana Sofia) em qualquer espaço lusófono, 
é que os sujeitos poderão se tratar de forma igualitária, com os mesmos traços em comum:

para que a lusofonia seja um espaço simbólico significativo para seus habitantes, é preciso que seja um espaço em que todas as variantes linguísticas sejam, respeitosamente, tratadas em pé de igualdade. (...) Evidentemente, a lusofonia tem origem em Portugal e isso é preciso reconhecer. No entanto, o que se espera na construção do espaço enunciativo lusófono é a comunidade dos iguais, que têm a mesma origem. (Lourenço, 2001, p. 46)

Por fim, para que serve lutar por uma lusofonia igualitária, múltipla de sentidos e baseada no Português? Para que, como o documentário revela, seja possível estabelecer, mais do que pontes (que são construídas quase sempre em linha reta e, às vezes, com somente uma direção) redes de contato e de significação, onde a troca de sentidos e de valores seja a tônica de uma construção coletiva contínua e legítima.

Com efeito, o documentário constrói o seu principal valor calcado no destaque à diversidade, cuja existência é entendida como a convivência dos contrários. São esses traços e valores que permitem pensar em uma lusofonia baseada na diversidade (hifenizada), mas sem negar a existência de uma unidade que nos une pela história e que se alimenta pela língua. É por esse caminho que a lusofonia, as lusofonias, esta e as outras, pode $(\mathrm{m})$ manter e expandir os sentidos de uma intimidade perante o diferente que não afasta, mas que convida à interação, e cujos traços devem se institucionalizar a ponto de serem reconhecidos e veiculados pelos espaços desse universo sempre em construção.

\section{REFERÊNCIAS}

Bauman, Z. (2001) Modernidade líquida. Rio de Janeiro: Jorge Zahar.

Brito, R. P. de. (2010). Temas para a compreensão do atual quadro linguístico de Timor-Leste. In A. D. Pereira (Ed.), Ciências Q Letras - Ásia: história e cultura (vol. 48, pp. 175-194). Porto Alegre: Faculdade Portalegrense.

Brito, R. P. de (2013). Língua e identidade no universo da lusofonia: aspectos de Timor-Leste e Moçambique. São Paulo: Terracota.

Brito, R. P. de (2017). Entre vivências e estudos: por uma lusofonia possível. In A. M. Ferreira; C. Morais; M. F. Brasete \& R. L. Coimbra (Eds.), Pelos mares da língua portuguesa III (pp. 1043-1051). Aveiro: Universidade de Aveiro. Retirado de http://hdl.handle.net/10773/18281

Brito, R. P. de \& Hanna, V. (2010). Sobre identidade em contexto lusófono: reflexões. In N. B. Bastos (Ed.), Língua portuguesa: cultura e identidade nacional (pp. 75-88). São Paulo: IP-PUC-SP; EDUC.

Castells, M. A (2005). Sociedade em rede. São Paulo: Paz e Terra.

Cunha, L. (2012). Singularidades inabaláveis e convergências desejadas: discursos e políticas da lusofonia. In N. Bastos (Ed.), Língua portuguesa: aspectos linguísticos, culturais e identitários (pp. 259-272). São Paulo: EDUC. 
Harvey, D. (2004). Condição pós-moderna. São Paulo: Edições Loyola.

Fiorin, J. L. (2011). Língua Portuguesa, identidade nacional e lusofonia. In D. L. P. de Barros (Ed.), Preconceito e intolerância: reflexões linguístico-discursivas (pp. 119-135). São Paulo: Universidade Presbiteriana Mackenzie.

Landowski, E. (2002). Presenças do outro: Ensaios de sociossemiótica II. São Paulo: Perspectiva.

Lesser, J. (2001). A negociação da identidade nacional: imigrantes, minorias e a luta pela etnicidade no Brasil. São Paulo: Editora UNESP.

Lopes, V. (Realizador). (2004). Língua - vidas em Português [Filme]. Brasil/Portugal: TV Zero/Costa do Castelo Filmes.

Lourenço, E. (2001). A nau de Ícaro. São Paulo: Cia. das Letras.

Martins, M. de L. (2006). Lusofonia e luso-tropicalismo, equívocos e possibilidades de dois conceitos hiperidentitários. In N. Bastos (Ed.), Língua portuguesa: reflexões lusófonas (pp. 49-62). São Paulo: EDUC.

Woodward, K. (2000). Identidade e diferença: uma introdução teórico e conceitual. In T. T. da Silva (Ed.), Identidade e diferença. A perspectiva dos Estudos Culturais (pp. 7-68). Petrópolis: Vozes.

\section{NOTA BIOGRÁFICA}

Pós-Doutora pela Universidade do Minho, Doutora e Mestre em Linguística pela Universidade de São Paulo. Docente e coordenadora do Núcleo de Estudos Lusófonos do Programa de Pós-Graduação em Letras, da Universidade Presbiteriana Mackenzie - UPM. Coordenadora de Programas e Projetos da Pró-Reitoria de Extensão da UPM. Pesquisadora Associada do Centro de Estudos das Literaturas de Expressão em Língua Portuguesa da USP e Conselheira do Instituto Nacional de Linguística de Timor-Leste. Coordenadora de projetos de difusão linguística do português junto à Universidade Nacional Timor Lorosa'e em 2004 e 2012.

ORCID: https://orcid.org/o0oo-0002-0634-8572

Email: reginahelena.brito@mackenzie.br

Morada: Universidade Presbiteriana Mackenzie, Av. Brasil, 1220, Jd. Guanabara, Campinas, São Paulo, Brasil

* Submetido: 03.06.2018

* Aceite: 07.07 .2018 